\title{
POPULAÇÃO EM SITUAÇÃO DE RUA: REPRESENTAÇÕES SOCIAIS SOBRE O COMER E A COMIDA
}

Maria Benedita do Carmo Duarte

Universidade de Taubaté-SP

Elisa Maria Andrade Brisola

Universidade de Taubaté-SP

Alexandra Magna Rodrigues

Universidade de Taubaté-SP
Recebido em: 27/07/2020

$1^{\text {a }}$ revisão em: 20/05/2021

Aceito em: 05/06/2021

\section{RESUMO}

Este artigo, parte de uma pesquisa de dissertação, pretende compreender as Representações Sociais sobre o comer e a comida para a População em Situação de Rua de um município do interior paulista. Participaram da pesquisa dezesseis sujeitos adultos em situação de rua. Para coleta de dados utilizou-se entrevista semiestruturada. A análise dos dados foi realizada por meio da análise de conteúdo e discutida à luz da teoria das representações sociais. O objeto social deste estudo - a comida - representa a sobrevivência na condição atual de vida e preserva a sua história nas recordações afetivas no passado. Os achados retratam o sofrimento de já ter tido que recorrer ao lixo para saciar a fome e revelam que apesar do avanço na criação de políticas públicas para este grupo ainda não é suficiente para contemplar seus direitos no que tange à alimentação.

Palavras-chave: representações sociais; comida; população em situação de rua. 


\section{HOMELESS: SOCIAL REPRESENTATIONS OF EATING AND FOOD}

\section{ABSTRACT}

This article, part of a dissertation research, aims to understand the Social Representations about eating and food for the Homeless Population of a city in the interior of São Paulo. Sixteen adult street subjects participated in the research. For data collection, semi-structured interviews were used. Data analysis was performed through content analysis and discussed in the light of the theory of social representations. The social object of this study - food - represents survival in the current condition of life and preserves its history in affective memories in the past. The findings portray the suffering of having already had to resort to garbage to satisfy hunger and reveal that despite the progress in the creation of public policies for this group, it is still not enough to contemplate their rights regarding food.

Keywords: social representations; food; homeless population.

\section{PERSONAS SIN HOGAR: REPRESENTACIONES SOCIALES SOBRE EL COMER Y LA COMIDA}

\section{RESUMEN}

Este artículo, parte de una investigación de tesis, tiene como objetivo comprender las representaciones sociales sobre la comida y el comer para la población sin hogar de una ciudad en el interior de São Paulo. Dieciséis sujetos adultos de la calle participaron en la investigación. Para la recolección de datos, se utilizaron entrevistas semiestructuradas. El análisis de datos se realizó a través del análisis de contenido y se discutió a la luz de la teoría de las representaciones sociales. El objeto social de este estudio, la comida, representa la supervivencia en la condición actual de la vida y conserva su historia en los recuerdos afectivos del pasado. Los hallazgos retratan el sufrimiento de haber tenido que recurrir a la basura para satisfacer el hambre y revelan que, a pesar del progreso en la creación de políticas públicas para este grupo, todavía no es suficiente contemplar sus derechos con respecto a la alimentación.

Palabras clave: representaciones sociales; comida; población sin hogar. 


\section{INTRODUÇÃO}

O presente estudo aborda os aspectos simbólicos da alimentação para a População em Situação de Rua (PSR), bem como sobre os Equipamentos Públicos de Segurança Alimentar e Nutricional (EPSAN) dos quais esse grupo utiliza. A PSR pode ser definida como um grupo populacional heterogêneo, caracterizado por sua condição de pobreza extrema, pela interrupção ou fragilidade dos vínculos familiares e pela falta de moradia convencional regular (Decreto n. 7.053, 2009).

A comida e o comer da população em situação de rua tornam-se objetos centrais desta pesquisa, uma vez que as experiências relacionadas à alimentação são próprias das relações humanas, ultrapassando limites culturais, sociais, políticos e religiosos. Por meio dessas experiências, é permitido aprender a respeito dos diferentes costumes e crenças de uma população e sobre as particularidades de diferentes organizações do cotidiano (Carneiro, 2005).

A comida sempre esteve, de algum modo, ligada às relações sociais presentes nos diferentes contextos sociais da humanidade. A alimentação adequada é promotora de saúde, assegura a sobrevivência, e assume papel fundamental na construção cultural de um povo. A comida é instrumento de partilha entre familiares e amigos por meio do convívio à mesa e representa momentos de união que podem ser considerados rituais de comensalidade. Assim, a prática da alimentação deixa de significar apenas a necessidade fisiológica, mas também envolve fatores relacionados ao prazer e ao afeto nela presentes (Montanari, 2008).

De acordo com Proença (2010), o comer e a comida como prática inserida em todos os grupos e atividades humanas constituem-se em ação cotidiana na vida das pessoas e estão envolvidos não somente aos fatores biológicos, mas também aos diferentes contextos econômicos, políticos, sociais, psicológicos e culturais das sociedades.

Nesse sentido, compreender a vivência e os aspectos simbólicos relacionados à comida e ao comer em situação de rua é desafiador, pois a PSR vive em condição de insegurança alimentar e nutricional, longe de familiares, sozinha ou com poucos amigos e tampouco faz suas refeições em casa e à mesa. Portanto, estudar esse fenômeno à luz da Teoria das Representações Sociais (TRS) é acadêmica e socialmente pertinente, uma vez que "as representações sociais devem ser vistas como uma maneira específica de compreender e comunicar o que nós já sabemos" (Moscovici, 2011, p. 46), observando que tais representações são entidades quase tangíveis presentes na maioria das relações sociais e que circulam por meio da fala, dos gestos e do encontro (Moscovici, 2012).

É importante considerar, ao abordar tal temática, a condição de pobreza em que vivem esses indivíduos, bem como a lógica mercantilista da sociedade capitalista, na qual a dignidade do homem e o lugar social assumido pelo indivíduo são 
expressos diante de um imaginário coletivo que valoriza o trabalho e a renda. Nesse sentido, Vieira (1992) dispõe que:

A pobreza não se reduz, portanto, a uma questão meramente econômica, se constituindo também num parâmetro de avaliação social. Nesse contexto, a população de rua, que indiscutivelmente se encontra numa situação de extrema pobreza, tem seu lugar demarcado, sendo estigmatizado pela sociedade como um todo e pela classe trabalhadora em particular (Vieira, 1992, p.18).

A Pesquisa Nacional sobre a PSR, realizada em 2007/2008 pelo Ministério de Desenvolvimento Social e Combate à Fome em 71 municípios com mais de 300 mil habitantes, identificou 31.922 adultos em situação de rua e veio a confirmar a condição de pobreza dessa população que recebe de 20 a 80 reais por semana, na maioria das vezes exercendo atividade remunerada (70.9\%) como catador de material reciclável, flanelinha, estivador, dentre outras. Tal pesquisa verificou, ainda, que a maioria da PSR no Brasil é do sexo masculino (82\%), negra (27,9\%), parda $(39,1 \%)$ e com idade entre 25 e 44 anos (53\%) (MDS, 2008).

O quadro de vulnerabilidade da PSR vem se agravando ao longo dos anos no Brasil. Estudo realizado por Natalino (2020), a partir de dados em painel do Cadastro Único e do Censo do Sistema Único de Assistência Social (Censo SUAS), a estimativa da PSR no Brasil, no início de 2020 foi de 221.869. pessoas. Constata-se o crescimento expressivo dessa população, de 140\%, que saltou de 92.515 em setembro de 2012 para mais de 221 mil pessoas em situação de rua em março de 2020, fato que pode ser explicado pelo aumento do desemprego, sobretudo no contexto da pandemia do Covid -19, atingindo $14,7 \%$ da população no primeiro trimestre de 2021, de acordo com a Pesquisa Nacional por Amostra de Domicílios Contínua (Pnad Contínua) do Instituto Brasileiro de Geografia e Estatística (IBGE, 2021).

A estimativa da PSR realizada por Natalino (2020) se deu momento no momento inicial da pandemia pela Covid-19. Segundo Silva et al (2020), para enfrentar esse cenário e o aumento da PSR durante a pandemia, "além de ações emergenciais, o fortalecimento do sistema de proteção social se impõe como meio a estabelecer estratégias para alterar as condições de vida das pessoas atualmente em situação de rua e ainda evitar que novos grupos vulnerabilizados se somem a essa população." (p.17).

Embora as pesquisas citadas tragam dados importantes sobre a realidade em quem vive a população em situação de rua e o preocupante aumento dessa população no Brasil, elas não abordam questões relacionadas à alimentação e ao comer em situação de rua, nem mesmo traz informações sobre o uso, por essa população, dos Equipamentos Públicos de Segurança Alimentar e Nutricional 
(EPSAN), como os Restaurantes Populares (RP) e as Cozinhas Comunitárias (CC) (MDS, 2005).

Estudo de revisão realizado por Sicari e Zanella (2018) com o objetivo de investigar a produção de estudos sobre a PSR no Brasil, entre 2006 a 2016, constatou que as pesquisas realizadas neste período apresentavam temas variados, categorizadas por tópicos: singularidades e diversidades; razões e motivações para a vida nas ruas; os diferentes modos de viver e sobreviver em situação de rua; construção social da imagem; interlocuções entre saúde e assistência social; relação com a cidade e os processos de saída das ruas.

Aguiar e Iriart (2012), por sua vez, mapearam questões relacionadas a alimentação da PSR em Salvador/Bahia e encontraram diversas formas e estratégias para se conseguir alimentos entre as quais, doações de variadas origens (instituições de caridade, particulares ou restos de restaurantes) que nem sempre disponibilizam comida em condições adequadas de consumo; o restaurante popular (embora nem sempre tenham disponível $R \$ 1,00$ para pagar) e a busca de alimentos no lixo ou em outros locais insalubres. Apesar de as possibilidades descritas, alguns indivíduos relataram ter passado fome, especialmente quando recém-chegados à situação de rua ou quando não dispunham de recursos para se deslocar até locais onde poderiam conseguir alimento.

Oliveira (2017) estudando a PSR do município do Rio de Janeiro, mostrou que dentre as formas de acesso à comida, as mais citadas foram as carreatas e as ações solidárias, seguidas da compra por meio da renda proveniente do trabalho, tais como: catação de materiais recicláveis; trabalho em eventos - montagem e desmontagem de estruturas para grandes eventos; guarda de carros como "flanelinha".

Dessa forma, o presente estudo propõe uma abordagem sobre os aspectos relacionados à comida e ao comer para a PSR à luz da TRS - teoria utilizada em estudos com temas de interesse social contemporâneos - possibilitando, assim, uma leitura interdisciplinar sobre esse tema complexo e latente em nossa sociedade.

\section{MÉTODOS}

Trata-se de uma pesquisa exploratória com abordagem qualitativa realizada nos espaços públicos habitados pela PSR na cidade de São José dos Campos/SP, com a participação voluntária dos sujeitos previamente convidados pela pesquisadora e informados minuciosamente a respeito dos propósitos existentes na elaboração da pesquisa. A seleção dos participantes do estudo foi realizada por acessibilidade.

Inicialmente, foi realizado um levantamento dos locais frequentados pelos sujeitos em contexto de rua. A partir desse levantamento, foi realizada abordagem na qual cada sujeito foi convidado a participar voluntariamente da pesquisa, após as 
explicações minuciosas da pesquisadora sobre a finalidade do estudo. Pelo fato de uma das pesquisadoras realizar trabalhos voluntários junto à PSR, o acesso a esses sujeitos tornou-se mais fácil, pois muitos contatos haviam sido feitos anteriormente no momento das ações voluntárias. Foram convidados para participar da pesquisa os sujeitos no contexto da PSR que atendiam os critérios de inclusão pré-estabelecidos: indivíduos acima de 18 anos que apresentassem estado de sobriedade e condições de responder às questões tratadas durante a entrevista. Tais condições foram avaliadas por meio de observação do pesquisador no momento da abordagem aos sujeitos. Aqueles que aceitaram participar do estudo voluntariamente assinaram o Termo de Consentimento Livre e Esclarecido (TCLE) previsto no projeto de pesquisa previamente aprovado pelo comitê de ética em pesquisa (parecer n. 2.221.149).

A entrevista semiestruturada foi realizada de forma individual, seguindo um roteiro contendo 15 perguntas abertas relacionadas à experiência em situação de rua, aos aspectos simbólicos sobre a comida e o comer em situação de rua e ao uso dos EPSAN. Todas as entrevistas foram gravadas em mídia digital e posteriormente transcritas. Para o alcance do número de participantes suficientes ao estudo, foi utilizada a técnica de saturação. A saturação é utilizada para determinar a dimensão de uma amostra, permitindo que a coleta de novos dados e novos participantes seja interrompida. Essa condição é definida quando os dados encontrados nas entrevistas se tornam redundantes, não sendo necessário persistir na coleta de dados, ou seja, a técnica de saturação permite ao pesquisador a finalização da coleta dos dados de acordo com a amostragem adquirida (Strauss \& Corbin, 2008).

Os conteúdos obtidos por meio de gravação durante a entrevista foram inicialmente transcritos em sua íntegra. As narrativas foram analisadas por meio da técnica de análise conteúdo apresentado por Bardin (Bardin, 2011) e discutidos à luz da TRS.

A análise de conteúdo, segundo Bardim (2011), é uma ferramenta que possui três fases. A primeira refere-se à pré-análise. Nela ocorre a exploração dos materiais utilizados, ou mesmo das leituras flutuantes, com o propósito de entender os pontos importantes para o desenvolvimento das próximas etapas da análise. A partir deste ponto da pesquisa, ocorreram várias leituras em momentos diferentes com a finalidade de refinar os elementos encontrados no conteúdo das narrativas. $\mathrm{Na}$ segunda fase, tem-se a triagem, momento no qual são retirados os diversos vícios de linguagem e as redundâncias verbais. E como terceira fase, tem-se o processo de categorização no qual é fixada a classificação de elementos peculiares a um eixo. Durante essa fase, houve a elaboração dos diferentes eixos apresentados no estudo. Essa etapa se deu por meio da identificação dos elementos constituintes das representações sociais sobre o objeto de estudo, caracterizando opiniões, crenças e valores relativos à ao a comida e ao comer em situação de rua. 


\section{RESULTADOS}

Participaram da pesquisa 16 sujeitos do sexo masculino com a média de idade de 42,6 anos; com idade mínima de 37 anos e idade máxima, 51 anos. Apenas homens foram entrevistados porque no momento da coleta de dados não havia mulheres nos espaços públicos nos quais a pesquisa foi realizada. Um aspecto que facilitou a abordagem e a realização das entrevistas foi o fato de uma das pesquisadoras ser voluntária em trabalhos voltados à PSR.

A partir das narrativas sobre os aspectos relacionados à comida e ao comer em situação de rua foram definidos quatro eixos de análises com as respectivas RS: comer em situação de rua, comida presente versus passado, fome e comida do lixo e sobre o uso dos EPSAN pela PSR.

No que tange às RS, concorda-se com Jodelet (2002) quando afirma que elas são constituídas como "uma forma de conhecimento socialmente elaborado e compartilhado, com um objetivo prático, e que contribui para a construção de uma realidade comum a um conjunto social" (Jodelet, 2002, p. 22). Já para Moscovici (1999), as RS sempre se preocuparam com os aspectos da sensibilidade social dos sentimentos sociais - sendo, portanto, indispensáveis para mobilizar as pessoas.

Desse modo, estudar a comida para a PSR à luz da TRS é algo pertinente e desafiador. No presente estudo, as RS são elaboradas por um grupo social que vive em situação de rua, e sobre um objeto social - a comida e suas interfaces, com o objetivo de identificar a realidade e os aspectos simbólicos relacionados a tal objeto para os que se encontram em tal condição.

\section{COMER EM SITUAÇÃO DE RUA}

$\mathrm{O}$ ato de comer na rua e tudo o que ocorre nesse ambiente é visto de forma comum pela PSR, tendo em vista que muitos atrelam essa situação ao costume, mas também à tristeza. É a escolha de vida para um determinado momento de suas trajetórias, ao mesmo tempo em que remete à tristeza, à indiferença e ao desprezo pela sociedade. Sobre o comer na rua, seguem alguns relatos:

Pra mim comer na rua é igual comer em qualquer outro lugar, entende? Todo jeito a gente come pra matar a fome, é 'quinem' comer na casa da gente, ué, tudo igual por causa que eu já tô nessa vida faz tempo e o tempo a gente fica com costume. (E5)

Pra mim comer na rua é normal, nada de estranho não, acostumei viver nessa vida e tá tudo certo não tem nada de errado não, tudo suave. (E8) 
Poxa, comer na rua as vezes é complicado sabe, mas as vezes é de boa, às vezes as pessoas passa e fica olhando esquisito pra gente, parece que a gente é bicho, e a gente tem que passar por isso e seguir o trecho pois é assim que as coisas segue, tá ligada? Eu como ali na calçada, no banco, onde eu tô mesmo e já peguei afeição assim, não tem crise não. (E6)

A PSR passa por um processo transformador mediante as adversidades apresentadas pela rua. E, através dessa situação, recriam os sentidos de vida, adequando-se à realidade que se apresenta, por mais inóspito que possa parecer (e de fato o é) o 'habitat' do viver nas ruas. Por outro lado, há um destaque para o olhar do transeunte, qual seja, um olhar de julgamento das pessoas que passam e que remetem a PSR à condição de exclusão. Vejamos: "Pra mim comer na rua é uma coisa de costume, a gente fica acostumado com isso mais é triste viu? É difícil pois as pessoas olham pra gente como se a gente fosse um bicho sujo, como se eu não fosse gente." (E13).

Para Moscovici (2011, p. 46), "as representações sociais devem ser vistas como uma maneira específica de compreender e comunicar o que nós já sabemos". E sua elaboração traduz as representações que estão entre nós (Jodelet, 2005). Nesse sentido, podemos sugerir que os conteúdos representacionais aqui apresentados tratam da existência de duas linhas estruturantes em torno das quais se organizam as representações sociais: a identitária, identificada quando o sujeito relata sobre o costume, a escolha e a normalidade de comer em situação de rua, na qual o comer em situação de rua faz parte do cotidiano de quem vive nessa condição e retrata a condição de exclusão desses sujeitos; e a afetiva, observada nos discursos relacionados à tristeza que é ter que se alimentar na rua, expostos aos olhares e julgamentos da sociedade que transita pelos espaços públicos habitados pela PSR.

\section{COMIDA PRESENTE VERSUS PASSADO}

O eixo referente à comida presente versus passado, derivou da abordagem com as seguintes questões: Hoje, morando na rua tem alguma comida que você goste muito? Qual é? A comida lhe traz alguma recordação? No passado, de qual comida você mais gostava? Além disso, durante a explanação das questões também foram tratados os aspectos referentes à origem da comida no cotidiano e qual o tipo de comida mais consumida.

As principais RS a respeito da comida do presente para a PSR revelam que a comida no contexto de rua representa exclusivamente a questão do fator biológico, o que significa: comer para não passar fome, comer para ter saúde e energia. No entanto, diferentemente das representações apresentadas sobre a comida no presente, a comida no passado é pautada pelas lembranças do convívio familiar, pelo afeto e pelo cuidado. E é nesse ponto que são apontados os laços familiares que em algum momento de vida foram rompidos e fragilizados e que, por conseguinte, tornaramse fatores que possivelmente contribuíram para que esses sujeitos, durante o 
infortúnio acometido à sua trajetória de vida, em algum momento buscassem as ruas como moradia e meio de subsistência.

As representações sociais apontam para duas linhas estruturantes que contribuem para compreender o modo de pensar do grupo social em questão. A comida do presente diz respeito à questão biológica e apresenta-se como forma de sobrevivência nas ruas em sua principal representação e está relacionada ao alimento como fonte de energia e nutriente. Enquanto isso, a comida do passado remete às lembranças familiares, à figura feminina e traz o afeto como componente principal das RS identificadas. Damatta (1987) define com muita clareza e pertinência a diferença entre alimento e comida. Para o autor, o alimento é considerado como substância nutritiva. Contudo, a "comida não é apenas uma substância alimentar, mas é também um modo, um estilo e uma maneira de alimentar- se." (Damatta, 1987, p. 22). E essa maneira considera os aspectos que envolvem o gesto de alimentar-se, os aspectos simbólicos envolvidos na alimentação e não apenas o alimento que é ingerido.

A comida do presente assume o papel biológico, trazendo à comida uma conotação de alimento, substância nutritiva. Entretanto, a PSR não tem direito à escolha do alimento que consome, pois ingere o que ganha. E os relatos abaixo refletem bem essa questão.

Dona, a gente quando anda pro mundo, mora no 'chão', nas estradas, nas pontes, no 'mundão', a gente tem que comer as coisas que tem ué, a gente come qualquer coisa já tô calejado disso já, mais quando as pessoas dá pra gente, tem pão com manteiga, café, arroz, feijão, macarrão, essas coisas que a gente come, não passo apuro não e gosto de tudo que as pessoas dá, não tenho enjoação não. (E5)

Sabe, eu como de tudo, gosto de tudo, sem causa problema pra nada não, eu gosto de coisa mais normal, sabe um arroz com feijão, pé de porco, torresmo, farofa, essas coisas que eu gosto. Aqui na rua a gente come o que as pessoas dão pra gente, mas é comida limpinha, boa também, arroz com feijão caprichado com uma mistura, um frango, uma carne de vaca com batata não falta não, a gente não pode reclamar de nada não, não falta nada aqui nessa cidade porque as pessoa ajuda, sempre tem de tudo graças a Deus. (E8)

As condições ora relatadas, portanto, ferem o Direito Humano à Alimentação Adequada (DHAA) e o amplo conceito de Segurança Alimentar e Nutricional (SAN) que, dentre outros aspectos, determina que essa comida seja constante, em quantidade e qualidade. Desse modo, a PSR não exerce o direito a uma alimentação adequada e promotora de saúde, conforme previsto na Política 
Nacional de Segurança Alimentar (Decreto n.7.272, 2006) e na Política Nacional para PSR (Decreto n. 7.053, 2009).

Em relação aos alimentos que são consumidos no cotidiano da PSR é marcante a presença da identidade da comida brasileira, do prato comum da mesa dos brasileiros. A composição das marmitas recebidas por doação ou das oferecidas nos abrigos representa um aspecto cultural da alimentação do brasileiro - o arroz com feijão, acompanhados de algum legume e uma 'mistura' de carne ou frango.

Desse modo, é possível perceber que a comida típica brasileira é aqui representada como a comida 'normal' recebida nas marmitas, a comida de 'sal' como informado por um dos entrevistados. É possível, pois, identificar a identidade cultural, por meio hábitos alimentares. Os costumes alimentares adquiridos por uma sociedade ao longo do tempo revelam sua identidade.

Por sua vez, a comida do passado propicia lembranças dos momentos vivenciados em família, à comida caseira preparada pela mãe, avó ou esposa e retrata fortemente a figura feminina, ligada ao cuidado e ao carinho, trazendo à tona uma das características próprias das RS, qual seja, o afeto. Assim, vejamos.

Ahhh, eu gosto muito de comer macarrão com massa de tomate, é muito bom e satisfaz a gente, a gente fico contente, mas eu gosto de carne com cebola picadinha, bife com batata frita, é bom comer as coisas que a gente gosta de verdade. Quando eu morava com minha mãe, que já foi morar no céu, minha vó Dita ajudava a gente para minha mãe pode trabalhar, e daí ela fazia aquele macarrão vermelhinho com carne moída e era bom demais, eu repetia duas, três vezes, tinha fartura, não faltava nunca e eu sinto falta da minha mãe, vozinha que já foram embora. (E6)

É muito positivo que essas representações estejam presentes na subjetividade da PSR. Na visão de Da-Matta (1987), o alimento e as práticas alimentares contemplam imensamente o envolvimento entre pessoas no momento das refeições. Tais situações são capazes de provocar diferentes sensações como a afetividade e o prazer, remetendo a boas lembranças e histórias. Sendo assim, a comida tem a capacidade de assumir um papel social importante nas relações humanas e nos diferentes grupos sociais. Ao retomar as lembranças através da abordagem relacionada à 'comida no passado', o sujeito se identifica com as relações amorosas e afetivas com os familiares, sendo esses os 'modelos saudáveis de identificação' (Damergian,1998).

\section{FOME E A COMIDA DO LIXO}

Neste eixo são abordadas as RS sobre a fome e a comida no lixo para a PSR. Foi possível verificar que a situação de fome em algum momento da vida nas ruas faz 
parte da trajetória desses sujeitos. Em decorrência disso, são observadas e relatadas situações de busca por restos de alimentos no lixo para saciar a fome.

As RS sobre fome e comida do lixo para a PSR apontam exclusivamente para o componente afetivo das RS.

Muito sofrido, muito sofrido mesmo, é triste demais e nenhum filho de Deus e nem algum bicho, animal do mundo pode sentir isso não, é sofrimento demais dessa vida da gente. (E6)

Sim, várias vezes eu busquei comida no lixo, já comi comida do lixo, eu estava bastante perdido nas drogas, eu já comi várias vezes resto de comida 'amarrada' em saquinho e jogada no lixo e hoje eu estando mais lúcido tenho dor no coração de saber o que eu já passei e eu quero ajudar os moradores de rua para ajudar quando eu arrumar um emprego. (E3)

No presente estudo, os objetos sociais como a fome e a comida do lixo estão relacionados um ao outro, ou seja, a fome leva à busca pela comida do lixo e ambos apontam para o componente afetivo das RS, aqui identificado pelo sofrimento e pela tristeza. O componente afetivo, por compor a estrutura das RS e junto aos aspectos cognitivos nelas presentes, é fundamental (Spink, 1995). De acordo com Quiroz e Martinez (1991), as nossas experiências afetivas, condutas e respostas corporais e verbais são efeitos não de uma excitação exterior como tal, mas da representação que nós possuímos dela.

Os sujeitos entrevistados afirmaram recorrer ao lixo para saciar a fome enquanto viviam como trecheiros, em locais afastados, estradas longe de qualquer tipo de comércio, ou seja, em locais onde não tinham a quem recorrer e muitas vezes em situações de uso excessivo de drogas e álcool. Relataram, ainda, passar pela situação de fome em outras cidades e estados, mas afirmaram ser difícil passar por isso nas ruas do município ora pesquisado, pois nele existem os abrigos públicos que oferecem serviços para PSR, inclusive no que tange à alimentação, com oferta das principais refeições do dia - café da manhã, almoço e jantar. Além disso, afirmaram contar com a ajuda dos voluntários que fazem doação de alimentos ou mesmo com recursos próprios angariados através de trabalhos informais realizados com a venda de materiais recicláveis ou como flanelinhas. Sendo assim, todos os sujeitos entrevistados afirmaram que conseguem realizar ao menos uma refeição ao dia.

Além dos aspectos simbólicos identificados pela falta do alimento, a condição da fome fere a dignidade de qualquer pessoa, sendo que um dos direitos fundamentais básicos do cidadão é o direito alimentação adequada e que, portanto, nenhum dos sujeitos em situação de rua deveria passar por experiências como as relatadas abaixo. 
Já comi sim pois passei por aperto um dia e tive que tomar essa atitude triste, muito triste. (E5)

Pra falar bem a verdade para senhora, eu já tive a tristeza de comer a comida jogada no lixo sim senhora, eu não tinha outro recurso e tive que fazer isso e é um sofrimento maior do mundo. (E7)

É sofrido falar disso, mas já passei fome e nessa hora a gente não pensa duas vezes para fazer alguma coisa não. Eu estava por aí no mundo e num momento precisei fazer isso e digo que é sofrido demais, não gosto de falar nisso não. (E10)

Neste momento, é importante destacar que os princípios preconizados pela PNPSR determinam o seguinte:

I - Promoção e garantia da cidadania e dos direitos humanos; II Respeito à dignidade do ser humano, sujeito de direitos civis, políticos, sociais, econômicos e culturais; III - Direito ao usufruto, permanência, acolhida e inserção na cidade; IV - Nãodiscriminação por motivo de gênero, orientação sexual, origem étnica ou social, nacionalidade, atuação profissional, religião, faixa etária e situação migratória; V - Supressão de todo e qualquer ato violento e ação vexatória, inclusive os estigmas negativos e preconceitos sociais em relação à população em situação de rua (Decreto n. 7.053, 2009, p. 14).

Diante disso, é possível perceber que os princípios preconizados pela PNPS estão distantes de serem concretizados, principalmente no que diz respeito à alimentação - um direito humano fundamental garantido constitucionalmente a todo cidadão brasileiro. Isso sem contar o fato de a condição de insegurança alimentar e nutricional ser constante para esse grupo, pois independente de terem acesso a algum tipo de alimentação, seja ela doada ou ofertada nos abrigos, esses indivíduos não possuem renda regular, nem habitação e tampouco meios de subsistência para as demais necessidades básicas comuns a outros cidadãos como prevê a PNSAN (Decreto n. 7.272, 2006).

\section{UTILIZAÇÃO DOS EQUIPAMENTOS PÚBLICOS DE SEGURANÇA ALIMENTAR E NUTRICIONAL}

Tratar das políticas públicas para a PSR é um assunto desafiador, pois, no contexto geral, a essa população não são garantidos os direitos preconizados pela Constituição Federal como os direitos à moradia, ao trabalho digno, à saúde e à 
alimentação adequada. A PSR, além de viver em condições vulneráveis e de fragilização, encontra-se imersa em situações de desamparo, necessitando, assim, de políticas públicas efetivas que considerem as particularidades intrínsecas deste grupo.

No Brasil a rede de atenção à PSR articula serviços públicos no âmbito dos sistemas de saúde e da assistência social e da segurança alimentar e nutricional, em geral executadas pelos municípios. No campo da saúde, o Consultório na Rua (CR) tratase de uma estratégia constituída por equipes multiprofissionais que fazem atendimento fixo ou móvel, oferecendo atenção integral à saúde, implementada como parte da Política Nacional de Atenção Básica (PNAB) (MS, 2012).

No âmbito da Assistência Social há serviços específicos oferecidos à PSR como o Centro de Referência de Assistência Social (CRAS), o Centro de Referência Especializado de Assistência Social (CREAS), os serviços de acolhimento e os Centros de Referência Especializados para População em Situação de Rua (Centros Pop) que são ponto de apoio para a população em situação de rua fazer refeições, cuidar da higiene pessoal, lavar roupas, guardar pertences pessoais, participar de oficinas e outras atividades coletivas, além de realizar atendimentos individuais e inclusão das pessoas em situação de rua no Cadastro Único (Cadúnico) (MDS, 2005).

$\mathrm{Na}$ esfera da segurança alimentar e nutricional estão os EPSAN como os Restaurantes Populares (RP) e as Cozinhas Comunitárias (CC), dentre as estratégias já existentes para amenizar a condição de vulnerabilidade enfrentada pela PSR (Decreto n. 7.053, 2009).

As relações envolvendo as práticas alimentares e o acesso à alimentação abordados durante a entrevista revelam que muitos indivíduos já passaram por situação de fome e por momentos nos quais a única alternativa para saciar a fome era a procura por alimentos no lixo. No momento da realização da pesquisa, entretanto, todos os participantes afirmaram não passar fome devido à doação recebida dos voluntários, aos pedidos que faziam nos estabelecimentos comerciais como padarias e restaurantes e pelo fato de adquirirem comida por meio de recursos próprios provenientes de trabalhos informais ou nos locais destinados à PSR, como os abrigos municipais.

Apesar de realizarem algumas refeições diariamente, essa alimentação pode não assegurar a quantidade e qualidade apropriadas e que respeitem os gostos, aspectos culturais e costumes do sujeito que se alimenta, conforme preconizado pela PNSAN e DHAA. Além disso, não existe a autonomia desses sujeitos em relação ao alimento consumido, pois eles não têm o controle e o poder para decidir qual e quando irão consumir o alimento, assim como de que forma e em que momento terão acesso à próxima alimentação. Outra circunstância de insegurança alimentar e nutricional a que estão expostos no cotidiano é a ausência de estratégias eficientes por parte do Estado a fim de garantir o DHAA. 
As estratégias relacionadas à criação dos RP tornaram-se evidentes a partir de 2003 com a implantação do Programa Fome Zero. Desde então, os debates a respeito do combate à fome e sobre a SAN ganharam notoriedade e os aspectos relacionados a uma alimentação saudável e adequada começaram a ser vistos como direito de todos. Frente aos acontecimentos, o Ministério do Desenvolvimento Social (MDS) visou à modernização e à implantação desses restaurantes junto ao Programa Fome Zero, sendo o responsável por realizar, desde 2004, as transferências de recursos não reembolsáveis para a administração dos governos estaduais ou municipais que apresentassem interesse de introduzir o programa (MDS, 2007; Paula, Figueiredo, Oliveira, 2014; Nunes, 2017).

Embora ocorra a transferência de recursos para os RP, estes são de responsabilidade da administração local na qual o estabelecimento está instalado. O princípio fundamental das Unidades de Alimentação e Nutricional é produzir e oferecer refeições saudáveis de segunda à sexta-feira, contemplando um alto valor nutricional conjugado a preços acessíveis às pessoas na condição de insegurança alimentar. Nesse sentido, a produção deve atender no mínimo a uma oferta de 1000 refeições por dia com café da manhã e almoço, garantindo, assim, o DHAA. Cabe ressaltar, ainda, que os RP contribuem com o desenvolvimento social da população, pois geram emprego e renda, uma vez que estão implantados de acordo com as perspectivas da PNSAN (Neto, 2007).

No município ora estudado existe um Centro Pop, CRAS e CREAS, bem como os consultórios de saúde para atendimento da PSR. Existe ainda, uma unidade Residência Popular (RP) no município. Entretanto, nenhum entrevistado mencionou realizar refeições nestes locais. Além disso, não existe na cidade Centros Comunitários que atenda a população em vulnerabilidade social e alimentar. Tal realidade indica a necessidade de uma estratégia do município em relação à criação, divulgação e incentivo ao uso dos EPSAN pela PSR.

Em relação à utilização dos serviços ofertados pelos abrigos e Centro Pop, todos os participantes afirmaram conhecer esses locais e seus serviços, porém apenas a metade já utilizou os serviços oferecidos, tais como: higiene pessoal, encaminhamento para serviços de saúde, pernoite em dias de chuva ou de frio intenso e alimentação. Os outros participantes informaram conhecer e não utilizar os serviços oferecidos, pois não se sentem à vontade nestes locais pelo fato de não aceitarem as normas existentes e por apresentarem resistência ao encaminhamento para os abrigos quando são abordados pelo Apoio Social da Prefeitura, conforme ilustrado em depoimento dos entrevistados.

Conheço, opa! Já frequentei, lá no Albergue porque é o seguinte, eu to fazendo como é que é, eu tenho uma cirurgia marcada né? ..... O albergue é uma coisa boa pra quem mora na rua. Tem assistente social que dá encaminhamento para você tirar seus documentos, você vai de perua até o Poupa tempo, leva você e traz. É, não tira documento hoje em dia na rua aí quem não quer 
porque não quer nada com nada. No albergue tem o apoio da saúde, você pode sair de manhã pra procurar um serviço, outros tem um ponto que olha carro, pode voltar meio-dia pra almoçar né? (E2)

Eu conheço mais não gosto de Albergue, não gosto meu, tem abordagem social que vem aqui me encher o saco, me falar disso aí, eu não gosto, eu falo que tenho a casa aqui no Ema e aqui na rua eu cuido aqui do restaurante, não gosto, não vou, entendeu? (E4)

Aqui às vezes passa uma perua para levar a gente pra lá sabe, e lá tem uma comida ajeitada, uma cama, mas não gosto de ir não, quando a mulher da prefeitura passa, é mais no frio sabe, mas eu não vou não lá não pode levar o 'Buda' (cachorro), daí deixar ele sozinho não deixo não, maldade fazer isso com meu bichinho.

A fim de analisar as políticas públicas voltadas à PSR, é necessário considerar os diversos motivos que levam diferentes pessoas a fazerem a mesma opção de morar nas ruas. Assim, dependência química, problemas relacionados à saúde mental, desamparo, e perda de entes queridos, quebra e fragilização de vínculos familiares e o desemprego, tudo isso corrobora para o aumento da PSR.

Cabe ainda destacar que, no mundo contemporâneo, as mudanças operadas na esfera do trabalho, aliadas ao desemprego estrutural, aumentam exponencialmente o número de trabalhadores que não serão absorvidos pelas demandas do mercado e, nesse contexto, a rua pode constituir-se como uma saída, mesmo que ofereça riscos de várias naturezas.

Diante da complexidade da questão da PSR, impõe-se um trabalho interdisciplinar e intersetorial que envolva vários serviços, programas, projetos e benefícios com o intuito de atender às múltiplas necessidades dessa população. Nesse sentido, é fundamental uma parceria entre a sociedade e o Estado para que sejam devidamente efetivadas as políticas públicas destinadas a esse grupo. Por outro lado, também são necessários debates e discussões envolvendo a sociedade, a fim de que concretizar melhorias para essa população que vivencia tamanha vulnerabilidade social, sobretudo para que ocorra a desconstrução do preconceito que comumente recobre a PSR e possibilite avanços na efetivação das políticas públicas implementadas a partir da PNPSR. 


\section{CONSIDERAÇõES FINAIS}

A pesquisa realizada à luz da TRS possibilitou a compreensão a respeito dos valores e simbolismos que a PSR atribui à comida e a como esta encontra-se relacionada com o modo de comer em um contexto de rua. Assim, por meio do objeto social ora representado pela comida, foi possível demonstrar as ações comunicativas por ela expressas em momentos como a falta da comida na condição de fome, a busca pelo alimento no lixo, as memórias evocadas pela comida no passado, bem como sua importância no ambiente familiar e nos relacionamentos afetivos.

Além disso, foi possível mencionar o modo como versa a comida no cotidiano atual. Em relação à alimentação cotidiana da PSR, independente da forma como que é recebida, não a coloca em uma realidade de SAN, pois o acesso aos alimentos não é garantido, muito menos é regular e constante, tampouco são alimentos com quantidade e qualidade adequadas. Sendo assim, a PSR ainda continua em uma condição permanente de insegurança alimentar e nutricional, ferindo as prerrogativas pretendidas pelo DHAA.

Nesse sentido, a condição de não poder escolher, de não ter a opção de comer o que gosta ou o que lhe é agradável ao paladar, a ausência do respeito à cultura desse indivíduo que se alimenta e que, na maioria das vezes, fica dependendo de doações para se alimentar, apenas vem a reforçar a condição da exclusão social dos sujeitos em situação de rua. Essas questões são agravadas, ainda, pelo fato de o Estado não ter estratégias eficazes para amenizar a condição de exclusão da PSR, tampouco prover garantias ao cumprimento do DHAA.

É necessário que políticas públicas direcionadas à PSR sejam reconhecidas e praticadas em um trabalho conjunto com todas as esferas do Governo, além de contar com parcerias firmadas com a sociedade em geral. Isso porque a condição de pessoas em contexto de rua não é somente um problema relacionado à ordem pública, e sim uma questão social que escancara a sua condição de miséria e vulnerabilidade de cidadãos de direito. A PSR, portanto, deve ser tratada com cuidado e respeito às suas particularidades.

O presente estudo investigou os aspectos simbólicos da alimentação para um grupo de pessoas em situação de rua e o acesso delas aos EPSAN. Outras investigações devem ser realizadas de forma mais ampla a fim de mapear as questões relacionadas à alimentação para PSR e possibilitar a discussão sobre a situação e o fortalecimento das políticas existentes e ações efetivas para garantir o DHAA destes sujeitos.

\section{REFERÊNCIAS}

Aguiar, M. M. \& Iriart. J. A. B. (2012). Significados e práticas de saúde e doença entre a população em situação de rua em Salvador, Bahia, Brasil. Cadernos de Saúde Pública, 28(1), 115-124. https://doi.org/10.1590/S0102-311X2012000100012

Bardin, L. (2011). Análise de Conteúdo. Lisboa, Portugal: Edições 70, LDA. 
Carneiro, H. S. (2005). Comida e sociedade: Significados sociais da história da alimentação. História: Questões \& Debates, (42), 71-80.

DaMatta, R. (1987). La cultura de la mesa en Brasil. El Correo UNESCO, 40(5), $22-23$.

Darmegian, S. (1998). O papel do inconsciente na interação humana: um estudo sobre o objeto da psicologia social (Tese de Doutorado). Instituto de Psicologia da Universidade de São Paulo, São Paulo.

Decreto $n^{\circ} 7.272$ de 15 de setembro de 2006. Regulamenta a Lei no 11.346, que cria o Sistema Nacional de Segurança Alimentar e Nutricional - SISAN com vistas a assegurar o direito humano à alimentação adequada, institui a Política Nacional de Segurança Alimentar e Nutricional PNSAN, estabelece os parâmetros para a elaboração do Plano Nacional de Segurança Alimentar e Nutricional, e dá outras providências. Brasília, DF: Presidência da República. Recuperado de 2010/2010/Decreto/D7272.htm http://www.planalto.gov.br/ccivil 03/ Ato2007-

Decreto $n^{\circ} 7.053$ de 23 de dezembro de 2009. Política nacional para população em situação de rua. Brasília, DF: Presidência da República. Recuperado de http://www.planalto.gov.br/ccivil_03/_Ato2007-2010/2009/Decreto/D7053.htm

Instituto Brasileiro de Geografia e Estatística - IBGE. (2021). Pesquisa Nacional por Amostra de Domicílios Contínua. Recuperado em: https://www.ibge.gov.br/

Jodelet, D. (2002). Representações sociais: um domínio em expansão. In D. Jodelet, (org.). As Representações sociais (pp.17-44). Rio de Janeiro: Eduerj.

Jodelet, D. (2005). Loucuras e representações sociais. Petrópolis, RJ: Vozes.

Ministério da Saúde. (2012). Política Nacional de Atenção Básica. Brasília, DF: Ministério da Saúde. Ministério do Desenvolvimento Social e combate à fome (2005). Política Nacional de Assistência Social (PNAS/2004). Brasília, DF: Ministério do Desenvolvimento Social e Combate à Fome Recuperado de https://www.mds.gov.br/webarquivos/publicacao/assistencia_social/Normativas/PNAS2004 .pdf

Ministério do Desenvolvimento Social e Combate à Fome. (2008). Meta instituto de pesquisa de opinião. Pesquisa nacional sobre a população em situação de rua. Brasília, DF: Ministério do Desenvolvimento Social e Combate à Fome. Recuperado de http://www.mds.gov.br/backup/arquivos/sumario_executivo_pop_rua.pdf

Ministério do Desenvolvimento Social e Combate à Fome. (2007). Restaurantes populares: Roteiro de implantação. Brasília, DF: Ministério do Desenvolvimento Social e Combate à Fome. Recuperado de http://www.ufjf.br/renato nunes/files/2011/04/Roteiro-de-Implantacao.pdf

Ministério do Desenvolvimento Social e Combate à Fome. Secretaria de Avaliação e Gestão da Informação. Meta Instituto de Pesquisa de Opinião. Sumário Executivo. (2008). Pesquisa Nacional sobre a População em Situação de Rua. Brasília (DF): Meta Instituto de Pesquisa de Opinião, SAGI.

Ministério do Desenvolvimento Social e Combate à Fome; Secretaria de Avaliação e Gestão da Informação. (2005). Cadernos de Estudos Desenvolvimento Social em Debate, (14). Rede de equipamentos públicos de alimentação e nutrição: Resultados de avaliações. Brasília, DF: Ministério do Desenvolvimento Social e Combate à Fome; Secretaria de Avaliação e Gestão da Informação.

Montanari, M. (2008). Comida como cultura. São Paulo, SP: Senac.

Moscovici, S. (1999). Lo social em tiempos de transición (Entrevista concedida a Mireya Losada). Venezuela. SIC, 617, 302-305.

Moscovici, S. (2011). Representações sociais: investigações em psicologia social. (P. A. Guareschi, Trad.) (10ª ed.). Petrópolis, RJ: Vozes.

Moscovici, S. (2012). A psicanálise, sua imagem e seu público. Petrópolis, RJ: Vozes.

Natalino, M. (2020). Estimativa da população em situação de rua no Brasil (setembro de 2012 a março de 2020). Diretoria de Estudos e Políticas Sociais, IPEA. (Nota Técnica n 73). Recuperado de https://www.ipea.gov.br/portal/index.php?option=com content\&view=article\&id $=35812$

Neto, A. L. N. et al. (Equipe técnica) (2007). Restaurantes Populares: Roteiro de Implantação. Recuperado de http://www.ufjf.br/renato_nunes/files/2011/04/Roteiro-deImplanta\%C3\%A7\%C3\%A3o-Restaurantes-Populares- visualiza\%C3\%A7\%C3\%A3o.pdf

Nunes, E. A. (2017). Restaurante popular de Maracanaú-CE: A certeza de uma refeição. In VIII Jornada Internacional de Políticas Públicas. Maranhão, CE: Universidade Federal do Maranhão. Recuperado 
http://www.joinpp.ufma.br/jornadas/joinpp2017/pdfs/eixo10/restaurantepopulardemaraca nauceacertezadeumarefeicao.pdf

Oliveira, M. A. (2017). Políticas de Assistência Social e Segurança Alimentar e Nutricional e acesso à alimentação de pessoas em situação de rua no município do Rio de Janeiro. (Dissertação de mestrado). Programa de Estudos Pós-Graduados em Política Social, Universidade Federal Fluminense, Rio de Janeiro.

Paula, N. G.; Figueiredo, M. L. \& Oliveira, R. F. C. (2014). Manual normativo de implantação e estruturação das unidades do Restaurante Cidadão - OVG. Goiânia, GO: Organização das Voluntárias de Goiás. Recuperado de http://www.sgc.goias.gov.br/upload/arquivos/201509/manual-normativo-de-implantaCAo-e-estruturaCAo-dos-restaurantes-cidadAos p 360172_Aguas-lindas.pdf

Proenca, R.P.C. (2010). Alimentação e globalização: algumas reflexões. Revista Ciência e Cultura, 62(4), 43-47. Recuperado

http://cienciaecultura.bvs.br/scielo.php?script=sci_arttext\&pid=S0009$\underline{67252010000400014}$

Quiroz, P. A. \& Martinez, V. N. (1991). La psicologia social in Serge Moscovici. México. Revista Mexicana de Psicologia Social, 3(ed. especial), 3-18.

Spink, M. J. P. (1994). Desvendando as teorias implícitas: uma metodologia de análise das representações sociais. In Jovchelovitch, S., \& Guareschi Arcides, P. (Eds.), Textos em Representações Sociais (pp. 117-145). Petrópolis, RJ: Vozes.

Strauss, A. \& Corbin, J. (2008). Pesquisa qualitativa: técnicas e procedimentos para o desenvolvimento de teoria fundamentada. ( $2^{\mathrm{a}}$ ed.). Porto Alegre, RS: Artmed.

Sicari, A.A. \& Zanella, A.V. (2018). Pessoas em Situação de Rua no Brasil: Revisão Sistemática. Psicologia: Ciência e Profissão 38(4): 662-679. https://doi.org/10.1590/1982-3703003292017.

Silva, T., Natalino, M, Pinheiro, M. B. (2020). População em situação de rua em tempos de pandemia: um levantamento de medidas municipais emergenciais. Brasília: Ipea. (Nota Técnica, n. 74).

Vieira, M. A. C., Bezerra, E. M. R. \& Rosa, C. M. M. (Orgs.). (1994). População de rua quem é, como vive, como é vista. São Paulo, SP: Hucitec.

\section{CONFLITOS DE INTERESSES}

Não há conflitos de interesses.

\section{SOBRE OS AUTORES}

Maria Benedita do Carmo Duarte é administradora pela Universidade Paulista é mestre pelo Pósgraduação em Desenvolvimento Humano: Formação, Políticas e Práticas Sociais da Universidade de Taubaté/SP.

e-mail: maria.duarte.unifesp@gmail.com

(3) https://orcid.org/0000-0002-5313-8033

Elisa Maria Andrade Brisola é assistente social pela Universidade do Vale do Paraíba e doutora em Serviço Social pela Pontifícia Universidade Católica de São Paulo. É professora do Programa de Pósgraduação em Desenvolvimento Humano: Formação, Políticas e Práticas Sociais da Universidade de Taubaté/SP.

e-mail: elisabrisola@gmail.com

(2) https://orcid.org/0000-0002-9571-0923

Alexandra Magna Rodrigues é nutricionista pela Universidade Federal de Ouro Preto e doutora em Ciências pela Universidade Federal de São Paulo. É professora do Programa de Pós-graduação em Desenvolvimento Humano: Formação, Políticas e Práticas Sociais da Universidade de Taubaté/SP. e-mail: alexandramagnarodrigues@gmail.com

(2) https://orcid.org/0000-0001-7143-3258 